\title{
Allocative Efficiency of Carbon Emission Allowances among Sectors in China
}

\author{
Lili Chen ${ }^{1,2}$, Feng $\mathrm{He}^{2 *}$, Jianjian Wang ${ }^{2}$ \\ ${ }^{1}$ School of Economics and Management, Tsinghua University, Beijing, 100084, China \\ ${ }^{2}$ Donlinks School of Economics and Management, University of Science and Technology Beijing, \\ Beijing, 100083, P.R. China
}

Received: 6 April 2017

Accepted: 11 July 2017

\begin{abstract}
With rapid economic development, energy consumption and environmental pollution have become increasingly prominent, making clear emission reduction targets necessary. Therefore, this paper forecasts input and output variables for China's six industries during the $13^{\text {th }}$ Five-Year Plan by using an EBMDEA model to analyze the distribution efficiency of the industries. Moreover, the ZSG-DEA model is used to optimize carbon emission quotas and establish a reasonable distribution plan. The results show that among the six major sectors in China, the initial allocation of carbon emission rights has relatively low DEA efficiency, with significant efficiency differences among sectors. Only agriculture, forestry, animal husbandry, and fisheries achieved an efficient initial allocation of carbon emission rights, whereas industry and transportation, warehousing, and the postal service exhibited low allocative efficiency. The industrial sector has the greatest room for adjustment and its reduction can be compensated for through an increase in emissions from the other sectors so as to keep total carbon emissions constant. Based on the conclusions of the study, we make suggestions for various stakeholders.
\end{abstract}

Keywords: carbon emissions, DEA, ZSG-DEA, distribution, industries

\section{Introduction}

World energy demand continues to grow alongside global economic and social development. According to data published by the International Energy Agency, global emissions of energy-related carbon dioxide reached 36.3 $\mathrm{GtC}$ in 2015. Such large-scale consumption of fossil energy is leading to global warming. As the country with the highest energy consumption and carbon emissions in the world, China actively takes part in reducing carbon emissions and has established carbon emission trading pilots over seven provinces and cities.

*e-mail: hefeng@manage.ustb.edu.cn
In recent years, the efficiency of carbon emissions has become an important issue in academia, and a subject for both domestic and foreign scholars. Kaya and Yokobori first proposed the concept of carbon productivity, defining it as $\mathrm{CO}_{2}$ emissions over nominal GDP [1]. Sun believes that the carbon dioxide emissions per unit of GDP, as a measure of carbon emissions, are also an indicator of the energy-saving emission reduction standards at a national level [2]. However, some scholars hold different views. For example, Mielnik and Goldember propose the concept of a carbon index specifically defined as carbon emissions per unit of energy consumption, to measure the contribution of developing countries to energy conservation and climate change mitigation [3]. Ang uses energy intensity as a carbon index to measure a country's carbon emissions 
performance [4]. $\mathrm{CO}_{2}$ emissions are based on GDP as a basis of energy consumption as the starting point, but the GDP-based carbon efficiency index is favorable for developed countries. Because the total GDP of developed countries is generally higher, energy consumption as the basis for the carbon emission efficiency index is more beneficial to developing countries. Many scholars pay more attention to the research of measurement methods of carbon emission efficiency, which is based on the concept of carbon emission efficiency. Zhou et al. studied carbon emission efficiency in 18 countries with the highest $\mathrm{CO}_{2}$ emissions in the world, and used the MCPI index to measure carbon emission efficiency, and, based on this, performed correlation analysis of the factors affecting carbon emission efficiency [5]. Zaim and Taskin, and Zofio and Prieto use the DEA method to measure the carbon emission efficiency of OECD countries and analyze the differences [6-7]. According to Marklund and Samakovlis, based on the secondary direction of the distance function model, the EU estimates the cost of carbon emission reduction [8].

Presently, the mainstream approach toward researching carbon emission efficiency used by both foreign and domestic scholars is DEA. Gomes and Lins have proposed a ZSG-DEA model to reallocate $\mathrm{CO}_{2}$ emission permits among countries listed and not listed in Annex I of the Kyoto Protocol [9]. Färe et al. have proposed a DEA model that was used by 28 member states of the Organization for Economic Co-operation and Development from 1992 to 2006 to determine the magnitude and time of $\mathrm{CO}_{2}$ emission reductions [10]. Chiu et al. studied the allocation of emission allowances among 24 member states of the European Union using the ZSG-DEA model [11]. Wu et al. used a competitive DEA model that simultaneously considers the desirable output expansion and undesirable output contraction to evaluate the efficiency of power-generating enterprises in 60 countries from 2007 to 2011 [12]. Based on the ZSG-DEA model, Pang et al. analyzed the rational and efficient allocation of $\mathrm{CO}_{2}$ emissions among different countries to achieve global Pareto optimality [13]. Wei et al. estimated the potentials and marginal costs of $\mathrm{CO}_{2}$ emission reductions for 29 provinces in China from 1995 to 2007 using the extended SBM model [14]. Wang et al. proposed a new and efficient allocation scheme of emission allowances among China's provinces by 2020 using an improved and optimized ZSG-DEA model [15]. Research by Zhou et al. shows that the spatial-temporal allocation strategy seems to be more economically attractive for controlling the increase of $\mathrm{CO}_{2}$ emissions in China [16]. Moreover, Wang et al. allocated $\mathrm{CO}_{2}$ emission allowances among China's provinces by 2020 by modifying the model published by Gomes and Lins into a "zero-sum game" evaluation model that considers slack effects [17]. Miao and Sheng treat $\mathrm{CO}_{2}$ as an undesirable output variable, using a non-radial ZSG-DEA model to allocate $\mathrm{CO}_{2}$ emissions between different Chinese provinces [18]. Lozano et al. analyzed data on pulp and paper enterprises in Sweden using the DEA method in order to explore efficient allocation of $\mathrm{CO}_{2}$ emissions [19]. Sun et al. analyzed the mechanism of initial allocation of emission rights among manufacturing enterprises using DEA and extended allocation of emission permits models [20]. Sun et al. proposed a centralized DEA model for industrial optimization and designed a dual model for the centralized DEA model to analyze shadow prices on $\mathrm{CO}_{2}$ emissions [21]. Zhang and Hao allocated carbon emission quotas among the 39 Chinese industry sectors by 2020 , and employed an input-oriented ZSG-DEA model to examine the efficiency of allocation solutions [22].

Currently, studies on the allocation of carbon emission allowances are mainly carried out at province level, while most sector-level studies focus on the relationship between carbon emissions and economic growth. Due to significant differences among sectors, it is necessary to allocate the national carbon emission reduction index among different sectors, and clearly state the responsibility of each sector in reducing emissions in order to rationally and efficiently fulfill target emission reduction in China. In this study, we use the epsilon-based measure of efficiency model with integrated radial and non-radial characteristics, which can effectively replace traditional research using CCR, BCC, and SBM models for the calculation of efficiency problems. According to the national carbon emission reduction target, the allocation of carbon emission rights was adjusted by sector, and allowances were reallocated using the zero sum gains-data envelopment analysis (ZSG-DEA) model based on EBM calculations in order to provide a reference for allocating carbon emission allowances among sectors in China.

\section{Methods and Data}

DEA can handle the efficiency issues of multipleinput multiple-output in a unified framework and has a stronger explanatory power due to a more flexible specific functional form of stochastic foreword analysis. Based on the calculation methods, classical DEA models could be divided into two categories, where the first category is represented by the constant returns to scale (CRS) model based on radial measurements [23], while the second category is represented by the SBM model based on non-radial measurements [24]. Both CRS and SBM models have certain drawbacks. The radial CRS model measures input-oriented efficiency scores by assuming that the output is constant, but all the input factors reduce proportionally due to an over-stringent assumption, which has deviated from the actual economy. On the other hand, the efficiency calculation of the SBM model includes nonradial slack variables, thereby avoiding the assumption that input factors reduce proportionally. However, the cost of this optimization is the original proportional information of the projection value of an efficient frontier. Moreover, the SBM model has insufficient exposure during the process of solving the linear programming problem. In other words, the optimal relaxations obtained using zero and positive values exhibit significant 
differences. In order to solve the problems of CRS and SBM models in measuring and calculating efficiency scores, Tone et al. have constructed an EBM model that integrates radial and non-radial characteristics [25]. For $\mathrm{n}$ decision-making units (DMUs) with $\mathrm{m}$ input factors $(\mathrm{x})$ and s outputs (y), the EBM model can be expressed as:

$$
\begin{gathered}
\gamma^{*}=\min _{\theta, \lambda, s^{-}} \theta-\varepsilon_{x} \sum_{i=1}^{m} \frac{w_{i}^{-} s_{i}^{-}}{x_{i 0}} \\
\text { s.t. }\left\{\begin{array}{c}
\theta x_{0}-X \lambda-s^{-}=0 \\
\lambda Y \geq y_{0} \\
\lambda \geq 0 \\
s^{-} \geq 0
\end{array}\right.
\end{gathered}
$$

...where $\gamma^{*}$ is the optimal efficiency score calculated using the EBM model, $\theta$ is the radial efficiency score calculated using the CCR model, s- represents the slack vector of non-radial input factors, $\lambda$ is the weight vector, $\mathrm{w}_{\mathrm{i}}^{-}$represents the weight of $\mathrm{i}$-th input variable (to reflect the importance of the input variables)

satisfying $\sum_{i=1}^{m} w_{i}^{-}=1$, and $\varepsilon_{x}$ is the core parameter that includes radial $\theta$ and non-radial slacks. $X=\left\{x_{i j}\right\} \in R^{m \times n}, Y=\left\{y_{i j}\right\} \in R^{s \times n}$ are input and output matrices, respectively. Besides, $\mathrm{X}>0, \mathrm{Y}>0$. As $x=\theta x_{0}-s^{-}$, the input-oriented EBM model can also be written as:

$$
\begin{aligned}
& \gamma^{*}=\min _{\theta, x, \lambda, s^{-}}\left(1-\varepsilon_{x}\right) \theta-\varepsilon_{x} \sum_{i=1}^{m} \frac{w_{i}^{-} s_{i}^{-}}{x_{i 0}} \\
& \text { s.t. }\left\{\begin{array}{l}
x-X \lambda=0 \\
x=\theta x_{0}-s^{-} \\
Y \lambda \geq y_{0} \\
\lambda \geq 0, s^{-} \geq 0
\end{array}\right.
\end{aligned}
$$

When $\varepsilon_{x}=0$ the EBM model can be simplified into an input-oriented CCR model. When $\theta=\varepsilon=1$, the EBM model is transformed into an SBM model. The core parameter and the value of $\mathrm{w}$ are estimated before calculating the EBM efficiency score.

The carbon emission reduction target or carbon emission allowances have a fixed total quantity in allocating responsibilities to reduce emissions. Hence, the conventional DEA model can only be used to calculate the relative efficiency of the initial allocation of responsibilities to reduce carbon emissions among sectors, and cannot improve the DEA efficiency of each sector by adjusting the allocation. Gomes and Lins [9] researched this issue and proposed a ZSG-DEA model that re-configures the inputs (or outputs) to find an efficient
DEA strategy, and emphasizes the proportional reduction strategy. According to this strategy, an inefficient DMU must subtract a certain number of inputs (or accept a certain number of outputs) to become an efficient DEA. In order to maintain total inputs (or outputs) constant, other DMUs must accept a certain number of inputs (or subtract a certain number of outputs) on a pro-rata basis according to their initial input (or output) values. The basic mathematical idea of the ZSG-DEA method can be described as:

$$
\begin{aligned}
& \operatorname{Maxh}_{r k} \\
& h_{r k} y_{i k} \leq \sum_{q} \lambda_{q} y_{i q}\left|1-\frac{y_{i k}\left(h_{r k}-1\right)}{\sum_{q \neq k} y_{i q}}\right| \\
& \sum_{q} \lambda_{q} y_{j q} \leq x_{j k} \\
& \lambda_{q} \geq 0 \text { for } \forall q
\end{aligned}
$$

Equation (3) represents the mathematical expression of the output-oriented ZSG-DEA method. The linear programming aims at allocating output variables, wherein $h_{r k}$ represents the technical efficiency of unit k as evaluated under the ZSG condition, $h_{k}$ represents the classical DEA technical efficiency of evaluated unit $\mathrm{k}, x_{i q}$ and $y_{j q}$ are $\mathrm{i}$-th input variable and the $\mathrm{j}$-th output variable of DMU q, respectively, and q is the planning coefficient. It can be seen that the evaluated DMU $\mathrm{k}$ allocates surplus output variables to other DMUs. $D M U_{k}$ reduces the output allocation of $y_{i k} h_{r k}$ and requires other (K-1) DMUs to increase their proportions according to their respective output variables, based on the principle of proportional increase, wherein the increment is directly proportional to the original value of the output variable of the other DMUs. The assumption of proportional increase implies the increased allocation of output variables among DMUs:

$$
\frac{y_{i k}\left(h_{r k}-1\right)}{\sum_{q \neq k} y_{i q}}
$$

Although this is nonlinear programming, its technical efficiency, $h_{r k}$, has been proven to be linearly correlated with the technical efficiency of classical DEA, $h_{k}$ under ZSG.

$$
h_{r k}=h_{k}\left[1+\frac{\sum_{j \in W}\left(\theta_{n m} h_{r k}-1\right)}{\sum_{j \varnothing W} x_{j k}}\right]
$$

...where DMUs without an expansion coefficient of 1 under the classical DEA condition were combined into the cooperative set W. $\theta_{n m}=h_{n} / h_{m}$ is the technical efficiency ratio of DMU $\mathrm{n}$ to DMU m. Equation (5) can simplify 


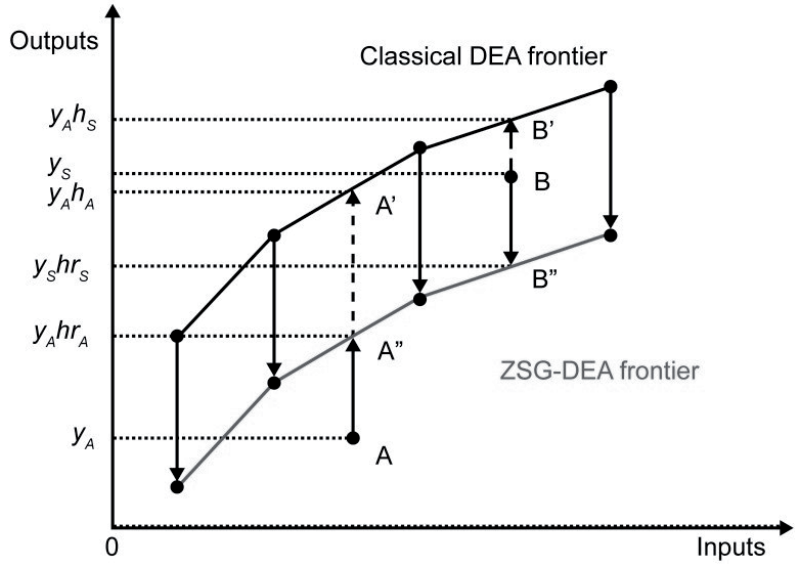

Fig. 1. Schematic diagram of output-oriented ZSG-DEA.

the calculation of technical efficiency, $h_{r k}$, for each DMU on the new ZSG frontier. The following figure compares the output-oriented classical DEA method with the ZSG-DEA method. It can be observed that the technical efficiency of unit A, which was originally low under the classical DEA method, could be improved by obtaining the output level of DMUs with higher efficiencies. Conversely, unit B, with a higher technical efficiency, reduces its output level. After allocation, all DMUs were on the ZSG-DEA frontier with efficiency values of 1 .

Based on allocative efficiency, our research analyzes the allocation model of carbon emission allowances among six major sectors in China in order to find a mechanism to reduce emissions with fair efficiency. China's $12^{\text {th }}$ Five-Year Plan proposed the target of "reducing the GDP carbon emission intensity by $17 \%$ in 2015 compared with the end of 2010." Our research continues this target by setting its objective to "reduce the national carbon emission intensity by $17 \%$ in 2020 compared with $2015 . "$ The responsibilities to reduce carbon emissions were allocated among sectors from 2016 to 2020, based on optimal allocative efficiency, as to yield the most efficient allocation of carbon emission rights. With respect to the classification of sectors, our research divides these sectors into six categories according to the method described in the Total Energy Consumption Table by Sector of the China Energy Statistical Yearbook [26-31]: 1) agriculture, forestry, animal husbandry, and fishery; 2) industry; 3) construction; 4) transportation, warehousing, and postal service; 5) wholesale, retail, accommodation, and catering; and 6) other sectors.

1) Population by sectors. Based on population data from the China Statistical Yearbook, the average annual population growth rate from 2009 to 2014 was calculated according to population trends over the past five years. Moreover, China's population from 2015 to 2020 was predicted by assuming that the population growth rate remains constant from 2015 to 2020 , and that the population proportion in each province and city remains consistent with 2014.

2) Carbon emissions by sectors from 2009 to 2013 were determined according to the Energy Consumption Table in the China Energy Statistical Yearbook, where the total energy consumption of various power sources in each sector was multiplied by the standard coal consumption coefficient, converted into the standard consumption volume, and subsequently multiplied by the carbon emission coefficients of each power source. Afterward, the carbon emissions from 2015 to 2020 were predicted according to the average growth rate of carbon emissions from 2009 to 2014.

3) GDP by sectors from 2009 to 2014 (calculated for each sector at prices in those years), obtained from the System of National Accounts in the China Statistical Yearbook, were divided by the consumer price index to obtain GDP data for each sector from 2009 to 2014, with 1985 as the base period. Furthermore, the GDP data from 2015 to 2020 were predicted based on the average GDP growth rate of each sector from 2009 to 2014.

4) Energy consumption by sectors from 2009 to 2013 was calculated according to the Energy Consumption Table in the China Energy Statistical Yearbook, and energy consumption from 2014 to 2020 was predicted based on the average growth rate.

5) Initial allocation of carbon emission allowances by sectors. First, the carbon emission intensity per unit of GDP was calculated according to the national total carbon emissions and total GDP from 2011 to 2015. Second, the target values of carbon emission intensity from 2016 to 2020 were calculated by adopting the target to "reduce the national carbon emission intensity by $17 \%$ in 2020 compared with 2015."

Table 1. Descriptive statistics.

\begin{tabular}{|c|c|c|c|c|c|}
\hline Variable & Units & Mean & Std. Dev. & Min & Max \\
\hline Energy consumption & $\begin{array}{c}\text { Million tons of } \\
\text { standard coal }\end{array}$ & $84,256.21$ & $120,468.00$ & $8,609.35$ & $362,336.30$ \\
\hline Population & Ten thousand people & $3,140.67$ & $2,821.26$ & 194.90 & $7,573.29$ \\
\hline $\begin{array}{c}\text { Initial allocation of carbon emission } \\
\text { allowances }\end{array}$ & Million tons & $494,630.00$ & $488,478.10$ & $62,023.13$ & $2,073,863.00$ \\
\hline Carbon emissions & Million tons & $45,493.25$ & $65,045.39$ & $4,648.53$ & $195,639.60$ \\
\hline GDP & Billion yuan & $76,546.47$ & $58,864.93$ & $20,817.87$ & $189,085.70$ \\
\hline
\end{tabular}


Table 2. EBM efficiency scores of each sector from 2016 to 2020.

\begin{tabular}{|c|c|c|c|c|c|}
\hline Sector & 2016 & 2017 & 2018 & 2019 & 2020 \\
\hline Agriculture, forestry, animal husbandry, and fishery & 0.973 & 0.98 & 0.987 & 0.993 & 1 \\
\hline Industry & 0.738 & 0.762 & 0.786 & 0.811 & 0.835 \\
\hline Construction & 0.833 & 0.855 & 0.876 & 0.898 & 0.92 \\
\hline Transportation, warehousing, and postal service & 0.737 & 0.761 & 0.785 & 0.809 & 0.833 \\
\hline Wholesale, retail, accommodation, and catering & 0.847 & 0.868 & 0.889 & 0.911 & 0.933 \\
\hline Other sectors & 0.777 & 0.8 & 0.823 & 0.846 & 0.87 \\
\hline
\end{tabular}

Finally, the allowance allocation was calculated based on carbon emissions from each sector from 2011 to 2015 , in order to obtain the initial allocation of carbon emission allowances among sectors from 2016 to 2020 .

In this study, industry population, sector initial carbon emissions, and industry energy consumption are used as input variables, industry GDP as the desired output, and $\mathrm{CO}_{2}$ as an undesirable output. Data is from the China Statistical Yearbook, China Energy Statistical Yearbook, and China's Provincial Statistical Yearbook. The data for the 13th and five-year periods are estimated based on previous data. Descriptive statistics are shown in Table 1.

\section{Results and Discussion}

Data analyses in this study were carried out using MAX-DEA software. The initial allocative efficiencies of carbon emission allowances among six sectors in China from 2016 to 2020 were calculated and the results are shown in Table 2.

The integration of radial and non-radial characteristics of the EBM model can be used to simultaneously and effectively solve issues in calculating the efficiency scores using CCR, BCC, and SBM models. It is obvious that the agriculture, forestry, animal husbandry, and fishery sector has relatively higher efficiency scores that are close to 1 , while the allocative efficiencies of carbon emissions among other sectors still need to be further improved.

The allocative efficiencies of all sectors should achieve efficiency, which means achieving an efficiency score of 1 in order to achieve a fair and efficient allocation of carbon emission rights among sectors. However, most sectors have low allocative efficiency scores at present. Therefore, our research employed the ZSG-DEA model on the basis of the EBM model to reallocate the carbon emission allowances. First, the increment or reduction of carbon emissions required for each sector in order to achieve an efficient allocation was calculated based on the initial allocative results and efficiencies. Subsequently, the efficiency scores were calculated by using the adjusted carbon emissions as new input variables. After several iterations, the efficiency scores of the ZSG-EBM model for all sectors were finally close to 1 , even if the allocation of carbon emissions rights among sectors achieved a unified efficient frontier of ZSG-EBM. The detailed iterative processes and adjustment results are shown in Table 3.

Based on the EBM model, the carbon emission allowances among sectors were reallocated and calculated using the ZSG-DEA model.

In terms of numerical values, the adjustment method for the transportation, warehousing, and postal service sector yielded negative scores, while one of other sectors yielded positive scores, indicating that the

Table 3. Allocative results and adjusted scores of carbon emission allowances among sectors.

\begin{tabular}{|c|c|c|c|c|c|c|}
\hline Sector & $\begin{array}{c}\text { Initial carbon } \\
\text { emission } \\
\text { allowance }\end{array}$ & $\begin{array}{c}\text { Initial } \\
\text { efficiency } \\
\text { score }\end{array}$ & $\begin{array}{c}\text { Efficiency } \\
\text { score of the } \\
\text { first iteration }\end{array}$ & $\begin{array}{c}\text { Efficiency score } \\
\text { of the second } \\
\text { iteration }\end{array}$ & $\begin{array}{c}\text { Efficiency } \\
\text { score of the } \\
\text { third iteration }\end{array}$ & $\begin{array}{c}\text { Final carbon } \\
\text { emission } \\
\text { allowance }\end{array}$ \\
\hline $\begin{array}{c}\text { Agriculture, forestry, animal } \\
\text { husbandry, and fishery }\end{array}$ & 4,938 & 0.986 & 0.989 & 0.994 & 1 & 5,459 \\
\hline Industry & 184,640 & 0.786 & 0.793 & 0.859 & 0.972 & 183,539 \\
\hline Construction & 5,228 & 0.876 & 0.887 & 0.934 & 0.951 & 5,958 \\
\hline $\begin{array}{c}\text { Transportation, warehousing, } \\
\text { and postal service }\end{array}$ & 25,209 & 0.785 & 0.798 & 0.902 & 0.933 & 23,923 \\
\hline $\begin{array}{c}\text { Wholesale, retail, } \\
\text { accommodation, and catering }\end{array}$ & 7,724 & 0.889 & 0.896 & 0.953 & 0.985 & 8,107 \\
\hline Other sectors & 45,221 & 0.823 & 0.838 & 0.911 & 0.992 & 45,974 \\
\hline
\end{tabular}


agriculture, forestry, animal husbandry, and fishery; construction; transportation, warehousing, and postal service; wholesale, retail, accommodation, and catering; and other sectors can increase their carbon emissions according to the initial carbon emission allowances while maintaining their DEA efficiencies. On the other hand, the transportation, warehousing, and postal service sector must reduce its corresponding carbon emissions to achieve an efficient DEA.

From Table 3 we see that the industrial sector accounted for the largest initial emission allowance among the six industries, reaching $67.6 \%$. Therefore, promoting industrial low-carbon development and active control of carbon emissions is imperative, as is strengthening the industrial sector to address climate change, and to establish phased, sub-regional, sub-sectors, sub-enterprise allocations of a low-carbon industrial development system. Moreover, it is also important to increase carbon emission control for such key industries as steel and cement. In Beijing, Shanghai, and other pilot provinces, it is essential to carry out industrial carbon emission peak management, exploration, and management experience, while giving full play to the role of the carbon market mechanisms in the industrial control of carbon emissions. At the same time, it is important to improve the low-carbon competitiveness of enterprises, strengthen enterprise carbon asset management, and promote low-carbon enterprise pilot demonstration. Rationally improving China's industrial structure and increasing investment in technology and clean energy use are also important here.

\section{Conclusions}

This study calculated, adjusted, and optimized the allocative efficiencies of carbon emission rights among six sectors in China from 2016 to 2020 on the basis of allocative efficiency. Our main conclusions are as follows. First, the initial allocation of carbon emission rights among six sectors in China has a relatively low DEA efficiency, with significant differences in efficiency among sectors from 2016 to 2020. Second, among the six major sectors, only the agriculture, forestry, animal husbandry, and fishery sector achieved an efficient initial allocation of carbon emission rights, whereas the industry and transportation, warehousing, and postal service sectors have low allocative efficiencies, which urgently need to be improved. Third, the industrial sector has the greatest room for adjustment, based on the final adjustment method, and the reduction can be compensated for by corresponding increments of other sectors to keep the total carbon emissions constant.

Based on the conclusion of this paper, the following suggestions emerge. The first objective is to establish differentiated carbon emission reduction targets and strategies, implement the carbon emission reduction targets in various industries, realize the rational and effective distribution of carbon emission rights among industries, and promote carbon emission allocation in different industries. The second is to increase investment in science and technology to encourage new energy development, and increase clean energy use to promote China's energy-saving emission reduction measures and its energetic development while accelerating carbon emission reduction and sustainable development processes. Finally, it is also important to adjust the industrial structure and accelerate the upgrading of industries to avoid excess energy-intensive industries while actively encouraging the development of strategic new industries.

Since the establishment of China's seven carbon trading pilot areas, the pilot area for the establishment of energy transformation has played a positive role. In 2017 China will vigorously promote carbon trading; the national unified carbon trading market will gradually increase in size. Here, petrochemical, chemical, building materials, steel, nonferrous metals, paper, electricity, and aviation are the eight key industries included in the carbon emissions trading range. The next phase of research should focus on these eight key industries, for China to achieve carbon emission reduction targets and rationally optimize the allocation of resources to improve its carbon emission efficiency.

\section{Acknowledgements}

This study was supported by the National Natural Science Foundation of China (grant No. 71673022) and the National Natural Science Foundation of China (grant No. 71272160).

\section{References}

1. KAYA Y., YOKOBORI K. Environment, Energy, and Economy: Strategies for Sustainability; United Nations University Press, 1997.

2. SUN J.W. The decrease of $\mathrm{CO}_{2}$, emission intensity is decarbonization at national and global levels. Energy Policy. 33 (8), 975, 2005.

3. MIELNIK O., GOLDEMBERG J. Communication The evolution of the "carbonization index" in developing countries. Energy Policy. 27 (5), 307, 1999.

4. ANG B.W. Is the energy intensity a less useful indicator than the carbon factor in the study of climate change? Energy Policy. 27 (15), 943, 1999.

5. ZHOU P., ANG B.W., HAN J.Y. Total factor carbon emission performance: A Malmquist index analysis. Energy Econ. 32 (1), 194, 2010.

6. ZAIM O., TASKIN F. Environmental efficiency in carbon dioxide emissions in the OECD: A non-parametric approach. J. Environ. Manag. 58 (2), 95, 2000.

7. ZOFÍO J.L., PRIETO A.M. Environmental efficiency and regulatory standards: the case of $\mathrm{CO}_{2}$, emissions from OECD industries. Res. Energy Econ. 23 (1), 63, 2001.

8. MARKLUND P.O., SAMAKOVLIS E. What is driving the EU Burden-sharing Agreement: efficiency or equity? J. Environ. Manag. 85 (2), 317, 2007. 
9. GOMES E.G., LINS M.P.E. Modelling undesirable outputs with zero sum gains data envelopment analysis models. J. Oper. Res. Soc. 59, 616, 2008.

10. FÄRE R., GROSSKOPF S., MARGARITIS D., WEBER W.L. Technological change and timing reductions in greenhouse gas emissions. J. Prod. Anal. 37 (3), 205, 2012.

11. CHIU Y.H., LIN J.C., SU, W.N., LIU J.K. An efficiency evaluation of the EU's allocation of carbon emission allowances. Energy Sources Part B Econ. Plann. Policy. 10, 192, 2015.

12. WU H.Q., DU S.H.F., LIANG L., ZHOU Y.F. A DEA-based approach for fair reduction and reallocation of emission permits. Math. Comput. Model. 58, 1095, 2013.

13. PANG R.Z., DENG Z.Q., CHIU Y.H. Pareto improvement through a reallocation of carbon emission quotas. Renew. Sust. Energ. Rev. 50, 419, 2015.

14. WEI C., NI J.L., DU L.M. Regional allocation of carbon dioxide abatement in China. China Econ. Rev. 23, 552, 2012.

15. WANG K., WEI Y.M., ZHANG X., YU S. Regional allocation of $\mathrm{CO}_{2}$ emissions allowance over provinces in China by 2020. Energy Policy. 54, 214, 2013.

16. ZHOU P., SUN Z.R., ZHOU D.Q. Optimal path for controlling $\mathrm{CO}_{2}$ emissions in China: A perspective of efficiency analysis. Energy Econ. 45, 99, 2014.

17. WANG P., DAI H.C., REN S.Y., ZHAO D.Q., MASUI T. Achieving Copenhagen target through carbon emission trading: Economic impacts assessment in Guangdong province of China. Energy. 79, 212, 2015.

18. MIAO Z., GENG Y., SHENG J. Efficient allocation of $\mathrm{CO}_{2}$, emissions in China: A zero sum gains data envelopment model. J. Clean. Prod. 112, 4144, 2015.
19. LOZANO S., VILLA G., BRANNLUND R. Centralised reallocation of emission permits using DEA. Eur. J. Oper. Res. 193, 752, 2009.

20. SUN J., WU J., LIANG L., ZHONG R.Y., HUANG G.Q. Allocation of emission permits using DEA: Centralised and individual points of view. Int. J. Prod. Res. 52 (2), 419, 2014.

21. SUN Z., LUO R., ZHOU D. Optimal path for controlling sectoral $\mathrm{CO}_{2}$ emissions among China's regions: a centralized DEA approach. Sustainability. 8, 28, 2015.

22. ZHANG Y.J., HAO J.F. Carbon emission quota allocation among China's industrial sectors based on the equity and efficiency principles. Ann. Oper. Res. 1, 2016.

23. CHARNES A., COOPER W.W., RHODES E. Measuring the efficiency of decision making units. Eur. J. Oper. Res. 2, 429, 1978.

24. TONE K. A slacks-based measure of efficiency in data envelopment analysis. Eur. J. Oper. Res. 130, 498, 2001.

25. TONE K., TSUTSUI M. An epsilon-based measure of efficiency in DEA - A third pole of technical efficiency. Eur. J. Oper. Res. 200, 901, 2010.

26. China Statistical Yearbook. 2015. Available online: http:// www.stats.gov.cn/tjsj/ndsj/2015/indexeh.htm

27. China Statistical Yearbook. 2014. Available online: http:// www.stats.gov.cn/tjsj/ndsj/2014/indexeh.htm

28. China Statistical Yearbook. 2013. Available online: http:// www.stats.gov.cn/tjsj/ndsj/2013/indexeh.htm

29. China Statistical Yearbook. 2012. Available online: http:// www.stats.gov.cn/tjsj/ndsj/2012/indexeh.htm

30. China Statistical Yearbook. 2011. Available online: http:// www.stats.gov.cn/tjsj/ndsj/2011/indexeh.htm

31. China Statistical Yearbook. 2010. Available online: http:// www.stats.gov.cn/tjsj/ndsj/2010/indexeh.htm 